RU Коммуникативное текстовое событие и способы его аттрактивного конструирования в медийном пространстве (на материале русского и корейского языков)

\author{
Орсоева А. А., Серебренникова Е. Ф.
}

\begin{abstract}
Аннотация. Цель исследования - раскрыть роль категории аттрактивности в конструировании дискурса коммуникативного события. Моделируются лингвокогнитивные механизмы аттрактивизации, описываются характеристики основных типов аттракторов на примере русского и корейского языков. Научная новизна исследования определяется новым подходом к разработке способов достижения аттрактивности и эффективности дискурса продвигающего типа. Впервые данные способы рассматриваются как лингвокогнитивные механизмы, активизирующие мышление адресата на основе прерывания когерентности процессов интерпретации медийного сообщения. В результате исследования выявлены основные типы когнитивных механизмов аттракции, дана их характеристика.
\end{abstract}

\title{
EN Communicative Text Event and Ways of Its Attractive Construction in the Media Space (by the Material of the Russian and Korean Languages)
}

\author{
Orsoeva A. A., Serebrennikova E. F.
}

\begin{abstract}
The study aims to reveal the role that the attractivity category plays in the construction of communicative event discourse. Linguocognitive attractivisation mechanisms are modelled, the characteristics of the main types of attractors are described using the example of the Russian and Korean languages. Scientific novelty of the study is determined by a new approach to developing ways to achieve attractivity and effectiveness in a discourse of the promoting type. It is the first time that these ways are considered as linguocognitive mechanisms that activate the addressee's thinking on the basis of breaking the coherence of media message interpretation processes. As a result of the study, the researchers have identified the main types of cognitive mechanisms of attraction, have characterised the said types.
\end{abstract}

\section{Введение}

Современное информационное общество испытывает существенное влияние медийного сетевого пространства, в котором в процессе создания, передачи и трансформации информация может быть наделена особой значимостью или качеством событийности. Вслед за усилением конкуренции в коммуникативном пространстве все больший интерес вызывает продвижение идей, технологий, знаний и результатов научной и иной деятельности. Особый интерес вызывают способы структурирования медийного сообщения с точки зрения достижения эффективности дискурса, то есть его событийности - способности влиять на когнитивное пространство адресата. Создание коммуникативного события является одним из активно обсуждаемых вопросов, связанных с влиянием информации на сознание человека. С усилением конкуренции в различных функциональных сферах общества увеличивается интерес к коммуникативному продвижению идей, технологий, знаний и результатов деятельности человека. Актуальность определяется необходимостью дальнейшего развития теории эффективности медийного дискурса, в частности исследования проблемы успешного продвижения текста/дискурса в коммуникации и вопроса о качественных характеристиках, конструирующих событийность дискурса.

Проблема речевого воздействия и эффективности в русле когнитивного подхода связывается с реализацией модусных коммуникативных категорий (Болдырев, 2006), которые характеризуют язык, дискурс в условиях 
интеракции, в ситуации коммуникации, отражая совмещенность концептуализации и оценивания в интерпретативных процессах. Обосновывается и получает развитие иерархическая модель достижения эффективности дискурса по формуле “AIDA” (англ. Attention - внимание, Interest - интерес, Desire - желание, Action - действие), характеризующей процесс привлечения внимания, активизации воображения, интеллектуальной деятельности, влияния на эмоциональную сферу (Чернявская, 2017, с. 18). Вводится и разрабатывается понятие «продвигающего» текста, реализующегося согласно формуле эффективности дискурса AIDA и обладающего качеством аттрактивности. Под продвигающим текстом понимается коммуникативная единица, служащая целям эффективного воздействия на целевую аудиторию (привлечь внимание потребителя, запомниться ему, вызвать или помочь сформировать определенное эмоциональное отношение к заложенной в тексте информации и, в идеале, побудить к определенному действию) и обладающая системой релевантных вербальных и невербальных средств его усиления/оптимизации (Ухова, 2018, с. 72). В русле исследования эффективности дискурса в коммуникативном пространстве выделяется проблематика дискурсов особого потенциала воздействия - дискурсов особого влияния (активного воздействия) (Соколова, 2015), к которым относятся, в частности, политический дискурс, PR-дискурс и в более широком плане - интернет-дискурс (Чернявская, 2017; Ухова, 2018). К дискурсам данного типа относим дискурс коммуникативного события, то есть дискурс, обеспечивающий подготовку и продвижение коммуникативной ситуации действенного характера, планируемой как некоторая акция (Дейк, 1989), информация в которой структурируется с целью повышения ее значимости для адресата.

Коммуникативное событие нацелено на структурирование дискурса определенного типа и степени воздействия. Создание и продвижение коммуникативного события входит в ряд актуальных вопросов, обсуждаемых в рамках таких направлений, как дискурсивные технологии воздействия и коммуникативный инжиниринг (Почепцов, 2008; Якоба, 2021), коммуникативный менеджмент (Зорин, 2005) и др. Одной из категорий, рассматриваемой с точки зрения связи и влияния на эффективность дискурса, является событийность, проистекающая прежде всего из факта взаимосвязи текста сообщения с экстралингвистическими - прагматическими, социокультурными, психологическими и другими факторами, влияющими на ее результативность и эффективность. Качество событийности дискурса рассматривается также с точки зрения модальности, то есть изменения отношения сознания к миру (Руднев, 1996).

В данном русле исследования текстового коммуникативного события актуальной является категория аттрактивности, которая рассматривается как качественная характеристика реализации дискурса, основанная на активизации дискурсивного мышления коммуникантов, обеспечивающая внимание к сообщению адресата. Термин аттрактивность, экстраполированный из синергетики, в рамках анализа дискурса рассматривается как «привлекательность, притягательность», влияющая на убедительность и воздействующий эффект сообщения. При этом выделяются два основных типа аттрактивности медиа-дискурса. Первый тип аттрактивности вызван фактической значимостью предмета информационного сообщения - некоторого социально значимого события (катастрофы, крупные события, мероприятия и т.д.), авторитетности социального статуса медиатора сообщения и т.д. Второй тип аттрактивности сознательно конструируется (Langacker, 1987) в дискурсе с целью придания предмету сообщения качества событийности. Данный тип дискурса направлен на активизацию дискурсивного мышления адресата и, как результат, принятие или непринятие им медиатизируемой дискурсивной позиции. При этом эффективность рассматривается как результирующий аспект целенаправленного конструирования дискурса с учетом внешних факторов, способных оказать влияние на воздействующий потенциал дискурса.

Таким образом, для достижения цели исследования необходимо решить ряд задач:

- изучить роль категории аттрактивности в конструировании дискурса коммуникативного события;

- установить типы аттракторов, структурирующих дискурс;

- дать характеристику установленных типов аттракторов на материале репрезентативных примеров.

Материал исследования представлен корпусом текстов / фрагментов текстов на корейском и русском языках, организующих, сопровождающих и продвигающих коммуникативное событие: рекламно-промоционными текстами, текстами PR-акции, текстами слоганов манифестаций политического, культурного и коммерческого характера (анонсы новостей, заголовки статей прессы).

Наряду с основными методами научного познания, такими как наблюдение, сравнение, инференция, используются методы интерпретации и когнитивного моделирования, контекстуальный и концептуальный анализ. Теоретической базой исследования послужили работы отечественных и зарубежных лингвистов в области теории дискурса и текста (Демьянков, 1983; Дейк, 1989; Арутюнова, 1988; Fairclough, 2013), теории речевого воздействия (Ухова, 2018; Чернявская, 2017), категории событийности (Руднев, 1996), продвигающего типа текста (Соколова, 2015; Ухова, 2018), синергетики (Хакен, 1980; Пригожин, 2000).

Практическая значимость исследования заключается в возможности использования его результатов при разработке курсов по общему языкознанию, семиотике коммуникации, лингвистике дискурса, медиалогии, а также при написании курсовых и дипломных проектов.

\section{Основная часть}

Обратимся к определению потенциала категории аттрактивности в конструировании текстового коммуникативного события. Рассмотрим подробнее понятия «событие» и «коммуникативное событие». Под событием 
в общем плане понимается акция, действие, дело или история, влекущая изменение в положении дел, результат которого имеет значение для человека (Грицианов, 2003, с. 723). Коммуникативное событие, понимаемое как ограниченный в пространстве и времени, мотивированный, целостный, социально обусловленный процесс речевого взаимодействия коммуникантов, приводящий к определенному результату или эффекту, изменяющему положение дел, и имеющий значимость для человека (Борисова, 2001, с. 17), заключается в «пересечении запрещающей границы» (Лотман, 1998, с. 282) в сознании, в когнитивной системе человека, в некоем отклонении при восприятии и интерпретации от стандартного, традиционного в картине мира и аксиосфере как ее глубинном измерении, организованной вокруг нормы - регулирующей ее ценности. Конструируемое нарушение нормативного в горизонте ожидания интерпретатора, соблюдение которого сохраняет целостность картины мира, приводит к нарушению логичного, понятного, привычного для адресата.

Свойством событийности может отличаться не только само референтное событие мира реальности, но и медийное, конструируемое - диктумное сообщение, приобретающее статус значимости в дискурсивизации и имеющее текстовую феноменологию (Демьянков, 1983, с. 320). В этом случае коммуникативное медиасобытие отграничивается как диктумное текстовое событие. Структуры, конструирующие эффект необычности, новизны, неожиданности (эффект «Н») на основе когнитивного механизма пересечения запрещающей границы в сознании, активизируют дискурсивное мышление адресата. Таким образом, дискурс коммуникативного события можно рассматривать как дискурс особого потенциала воздействия в конкурентном коммуникативном пространстве, нацеленный на придание значимости информации, побуждающий адресата к интерпретации и продвигающий референциальное событие на основе придания ему качества аттрактивности.

Аттракцию к дискурсу обеспечивает категория аттрактивности, получившая обоснование в рамках синергетического подхода к открытым самоорганизующимся системам (Хакен, 1980; Пригожин, 2000). В коммуникативном дискурсивном пространстве аттрактивность может создаваться с целью продвижения идеи, продукта, следуя своей предназначенности конструировать коммуникативное событие вокруг «диктумного» предмета дискурсивизации, то есть предмета, о котором говорится в сообщении и который служит объектом продвижения в коммуникативном пространстве. Конструирование аттрактивности происходит в точке бифуркации - моменте прерывания когнитивной когерентности в сознании человека. При этом осуществляется переориентация процессов интерпретации с целью упорядочивания смысла. Главным условием является создание ситуации когнитивной неопределенности по отношению к предмету сообщения на основе эффекта «Н» (эффекта неожиданности, новизны, необычности), находящей разрешение в коммуникации. Аттрактор - наилучший смысл, наилучший «ответ» для адресата в принятии решения, который предъявляется адресантом в конструируемом таким образом диктумном текстовом событии и может быть освоен адресатом либо по линии приятия, либо неприятия. Таким образом, конструирование дискурса коммуникативного события основывается на категории аттрактивности, создающей синергийный эффект «Н» в стратегии продвижения события в коммуникативном пространстве.

В результате анализа корпуса медиа-текстов, опредмечивающих дискурс коммуникативного события, можно выделить 4 основных вида аттрактивных механизмов, создающих «эффект Н» в переориентации в дискурсивизации структуры дискурса и активизирующих дискурсивное мышление адресата в процессах освоения информации: 1) аттрактивные механизмы, основанные на конструировании перформативности; 2) аттрактивные механизмы, основанные на конструировании и преодолении контраста; 3) аттрактивные механизмы, основанные на конструировании людического аспекта; 4) аттрактивные механизмы, основанные на фокализации ценностных установок адресата. Рассмотрим подробнее реализацию механизмов аттрактивизации дискурса коммуникативного события.

Выделяется вид аттрактора, основанного на структурировании перформативности. Суть конструирования перформативности сообщения состоит в вовлечении адресата в коммуникативное событие путем наделения его ролью со-актора, равноправного участника диктумной ситуации. Прерывание когнитивной когерентности в данном случае и, соответственно, активизация механизма аттракции основаны на контрасте между институциональным характером медийного дискурса, коллективной публичной адресацией сообщения, с одной стороны, и персонально-индивидуальной формой обращенности данного реализуемого сообщения, с другой. Сообщения, основанные на перформативности, отличаются личностной обращенностью к адресату с целью перехватить, зацепить внимание и вовлечь его в позицию участника. Рассмотрим некоторые способы и средства реализации структур-аттракторов, конструирующих перформативность:

квази-диалогичность, импликация позиции как «Я-говорящего», так и «Ты-слушающего»; реализуется посредством императива единственного числа: Ты знаешь, что можешь! (реклама сотовой связи компании МТС); Делай то, что можешь только ты! (реклама банка); 당신을 집중합니다 / Мы сосредоточены на тебе (реклама больницы); 당신이 중심에 있습니다/ Bы - в самом центре (продвижение культурного фонда «Кодовон»);

структурирование квестива; данный способ конструирования перформативности формируется путем вопрошания, обращения с запросом мнения по поводу обсуждаемой проблемы, призывает к совместному поиску выхода из ситуации, решения проблемы, акцентирует важность мнения именно адресата: $A$ где вы одеваетесь? (реклама магазина одежды); 사람이 많은 데 왜 외롭죠? / Людей так много, почему же одиноко? (южнокорейская социальная кампания, призывающая людей к «живому» общению); 돈이라면 남기시겠습니까? / A если бы на дне тарелки были деньги, вы бы их оставили? (социальная кампания, призывающая бережно относиться к ресурсам).

Значимым потенциалом достижения эффективности дискурса коммуникативного события является вид аттрактора, организующего взаимодействие в виде создания людического, игрового эффекта в коммуникации. 
Сущность данного вида аттрактора заключается в сознательном нарушении правил, норм языка для воздействия на адресата. В этом случае креативность становится имманентной характеристикой аттрактивности, активизирующей дискурсивное мышление на основе конструирования нового, необычного, удивляющего, неожиданного, противопоставленного прямому, логичному, привычному изложению информации. К способам и средствам достижения аттрактивности на основе креативной людической функции можно отнести следующие:

- графическое выделение: Скртм врмя офрмлня - сокращенная форма написания слов в тексте продвижения кредитной системы банка, исключающая гласные при написании, не только привлекает внимание благодаря необычной форме, но и проводит смысловую параллель, подчеркивая намерение решить все вопросы и предоставить предлагаемые услуги с максимальной скоростью;

- рифмованное построение текста: Вакцинация - защита нации; 자연스럽게. 아름답게/ Естественно. Красиво. Рифма создает удобную для восприятия «упаковку» информации, при этом облегчает путь ее усвоения и запоминания, побуждая к обдумыванию и приобщению к проблеме, например к вопросу о важности вакцинирования, возведенной до уровня национального масштаба.

Механизмы аттрактивизации могут основываться на аллюзии, побуждая сознание адресата к сравнению, сопоставлению ранее известной и новой информации, создавая при этом образ легкости восприятия, основанной на ранее известных фактах, опыте. Перед адресатом ставится вопрос о том, какова связь, в чем различие и сходство, ответ на который несет в себе аттрактор. Газ, два и обчелся. Что мешает Европе найти общий язык с Россией? первая часть заголовка статьи указывает на экономическую сферу, конкретно - поставки газа, при этом создавая вопрос, загадку, чем мотивировано обсуждение данной темы, вторая же часть задает вектор размышления, подсказывая, что тема актуальна в рамках обсуждения отношений России и Европы. 도깨비도 사랑스러운 살냄새/ Аромат, который нравится даже Токкеби - аллюзия, обладающая воздействующим потенциалом для южнокорейского адресата благодаря огромной популярности сериала, главным героем которого является корейский мифологический персонаж Токкеби. Из-за подобной формулировки объект продвижения приобретает статус принадлежности к сфере волшебного, сказочного вследствие отсылки к персонажу, вызвавшему живой интерес среди зрителей. Языковая игра воздействует на адресата, вовлекая его в позицию собеседника, вынужденного «играть»: ставить вопросы, искать и обдумывать ответы, разгадывать и расшифровывать загадки. Аттрактивные механизмы, воплощающие людическую функцию, воздействуют, нарушая нормы, стереотипы мышления и восприятия, создавая новый, иной смысл в процессах концептуальной интеграции.

Одним из наиболее эффективных способов достижения аттрактивности является конструирование контраста для интерпретатора в ситуации коммуникации. В данном случае эффект «Н», то есть эффект новизны, неожиданности, необычности, создается на основе противопоставления, противоречия за счет нарушения когерентных процессов познания. Аттрактивные механизмы, основанные на контрасте, вынуждают интерпретатора реагировать, отвечать, принимать решения в попытке преодолеть противоречие, вызванное когнитивными контрастами: ожидаемым и неожиданным, нормальным и ненормальным. В ряду основных способов и средств конструирования контраста можно выделить оксюморон, абсурдизацию, антонимию, парадокс. Господин Слуга; Печальный анекдот; Печальная комедия: противопоставление по смыслу создает ситуацию когнитивной неопределенности, вызывая интерес, воздействуя как на рациональное осмысление, так и на эстетическое чувство адресата. В данном случае названия спектаклей призваны привлечь внимание к постановке, более того, вынудить человека посетить театр, чтобы найти разгадку и упорядочить в сознании несоответствие, представленное антитезой - возможность того, что слуга станет господином, а комедия создаст печальное настроение.

Особо значимым воздействующим потенциалом обладает конструирование крайней степени контраста для познающего интерпретатора в виде конструирования абсурда: Купи унитаз, книга в подарок - структурируется абсурдное на первый взгляд, нетипичное, неожиданное объединение унитаза и книги, бытовой и во многом табуированной в публичном пространстве сферы и сферы высокой культуры, искусства, самосовершенствования. Нелогичность, непривычность подобной услуги прерывает когерентность восприятия, вынуждает обдумать, найти скорее непрямой, ироничный путь интерпретации и категоризации, активизируя рациональную и эмоциональную сферы в поиске возможного истинностного понимания - ответа из множества вариантов ассоциативного эха в интерпретации. Примером может послужить также статья, поднимающая проблему подбора актеров, основанного на уровне популярности, а не на выдающихся актерских способностях: Конь в Сенате, Бузова во МХАТе. Подобное сравнение, акцентированное рифмованной формой, порождает аттракцию к сообщению, создает дополнительный эффект иронии, насмешки. Актриса О. Бузова сравнивается с конем Инцитатом, согласно легенде назначенным римским сенатором, что указывает на абсурдность происходящего и явное негативное отношение адресанта к происходящему, побуждающее адресата определить свою позицию по отношению к референциальному событию.

Широко распространенным способом достижения аттрактивности коммуникативного события является фокализация сообщения на ценностных смыслах. Ценности рассматриваются как исходные нравственные категории, выступающие в роли ориентира осмысления и освоения мира, оценка - как когнитивный акт, в результате которого устанавливается отношение субъекта к оцениваемому объекту с целью определения его значения для жизни и деятельности субъекта (Арутюнова, 1988). Аттракторы ценностного плана соотносятся с нормой, привычной картиной мира, противопоставляя ценности и анти-ценности, рассматривая ценность в статусе желаемого, необходимого, должного. Наиболее часто аттракторы данного типа основываются на традиционных общечеловеческих ценностях, таких как чувство единства, патриотизм: 특별한 순간, 
함께해요 / Особенный момент. Разделим его вместе; Носи маску правильно. \#Мы вместе. При восприятии и интерпретации сообщения, фокализирующего лингвокогнитивные процессы в координатах концепта ЕДИНСТВО, создается эффект переживания приобщенности, не-одиночества, участия в событии, вовлечения в разделенное знание, мнение и отношение. Ценностной фокализацией отличаются, например, следующие сообщения: Пишите СМС за рулем. Бюро ритуальных услуг; Сколько должно умереть, чтобы ты привился?; 당신도 생명을 장난감처럼 생각하십니까? / По-вашему, жизнь - это игрушка? (проблема защиты животных), апеллирующие к ценности жизнь как самому главному для каждого человека. При этом фокализация имеет комплексный характер, поскольку концепт ЖИЗНЬ естественным образом связан со смежными аксиологемами любви, понимания, заботы. Частотны аттрактивные механизмы, апеллирующие к ценностям здоровье: 건강한 사람이 부자입니다 / Здоровый человек - богач; Защитите себя! Наденьте маску!; красота: 얼굴, 가리지 말자, 환하게 웃자/ Давайте не закрывать лищо, давайте ярко улыбаться.

Конструирование контраста, перформативности и людического аспекта используется в медиатекстах продвигающего типа на корейском языке, однако не является столь частотным, как в текстах русскоязычного медиапространства. При этом не только характерной, но и преобладающей в корейском медиапространстве при структурировании продвигающего текста является фокализация ценностных смыслов. Причина заключается в связи продвижения коммуникативного события на основе аттрактивности с концептосферой народа. В лингвокультуре корейцев под влиянием конфуцианства доминирующей ценностью является сохранение традиций и следование им, поэтому, несмотря на активные глобализационные и модернизационные процессы общества, южнокорейское медийное пространство характеризуется более выраженной приверженностью к сдержанности, превалированием категории вежливости. Благодаря этому в южнокорейском медийном пространстве при продвижении коммуникативного события наибольшим воздействующим потенциалом обладают аттракторы, фокализирующие ценностные установки.

\section{Заключение}

Обобщая полученные результаты, можно сделать следующие выводы: категория аттрактивности обеспечивает событийность дискурса путем создания для познающего сознания эффекта «Н» - неожиданного, нового, необычного в векторе выхода на истинностное положение дел для принятия решения.

В результате анализа корпуса медиа-текстов, опредмечивающих дискурс коммуникативного события, были выделены основные типы аттрактивных механизмов, создающих «эффект Н» в переориентации в дискурсивизации: 1) аттрактивные механизмы, основанные на конструировании перформативности; 2) аттрактивные механизмы, основанные на конструировании и преодолении контраста; 3) аттрактивные механизмы, основанные на конструировании людического аспекта; 4) аттрактивные механизмы, основанные на фокализации ценностных ориентиров в процессах восприятии и осмыслении информации.

Предназначенностью данного рода механизмов являются, с одной стороны, привлечение внимания, активизация эмоциональной и рациональной сфер за счет конструирования загадки, требующей ответа, когнитивного диссонанса, требующего разрешения. С другой стороны, в динамике дискурсивизации происходит переориентация в осмыслении диктумной ситуации как значимой, инициирующей субъектно-личностное вовлечение в нее, а аттрактор выступает как область упорядочения структурируемой ситуации когнитивной неопределенности при данном условии прерывания когерентности в ее интерпретации.

Перспективу дальнейшего исследования составляют возможное расширение типов аттракторов дискурса коммуникативного события, более детальное изучение видов выделенных типов аттракторов.

\section{Финансирование | Funding}

RU Исследование проведено при финансовой поддержке гранта Иркутского государственного университета для молодых ученых № 091-20-325 «Механизмы достижения эффективности дискурса коммуникативного события».

EN The reported study was funded by Irkutsk State University, young researcher grant number 091-20-325, "Mechanisms for Achieving Effectiveness of Communicative Event Discourse".

\section{Источники | References}

1. Арутюнова Н. Д. Типы языковых значений. Оценка. Событие. Факт. М.: Наука, 1988.

2. Болдырев Н. Н. Языковые категории как формат знания // Вопросы когнитивной лингвистики. 2006. № 2.

3. Борисова И. Н. Русский разговорный диалог: структура и динамика. Екатеринбург: Изд-во Урал. ун-та, 2001.

4. Грицианов А. А. Новейший философский словарь. М.: Книжный дом, 2003.

5. Дейк Т. А. Язык, познание, коммуникация. М.: Прогресс, 1989.

6. Демьянков В. З. Событие в семантике, прагматике и в координатах интерпретации текста // Известия АН СССР. Серия литературы и языка. 1983. № 4. 
7. Зорин А. В. Коммуникативный менеджмент // Эффективная коммуникация: история, теория, практика: словарь-справочник / сост. Л. Е. Тумина, М. И. Панов. М.: Агентство «КРПА Олимп», 2005.

8. Лотман Ю. М. Структура художественного текста. СПб.: Искусство-СПБ, 1998.

9. Почепцов Г. Г. Коммуникативный инжиниринг: теория и практика. К.: Альтерпрес, 2008.

10. Пригожин И. Р. Конец определенности. Время, хаос и новые законы природы. М. - Ижевск, 2000.

11. Руднев В. П. Морфология реальности: исследования по «философии текста». М.: Гнозис, 1996.

12. Соколова О. В. Дискурсы активного воздействия: теория и типология: автореф. дисс. ... к. филол. н. М., 2015.

13. Ухова Л. В. «Продвигающий текст»: понятие, особенности, функции // Верхневолжский филологический вестник. 2018. № 3.

14. Хакен Г. Синергетика. М.: Мир, 1980.

15. Чернявская В. Е. Дискурс как объект лингвистических исследований // Текст и дискурс. Проблемы экономического дискурса: сб. науч. тр. СПб.: Изд-во С.-Петерб. гос. ун-та экон. и фин., 2017.

16. Якоба И. А. Когнитивно-коммуникативная параметризация медийного дискурса: автореф. дисс. ... д. филол. н. Улан-Удэ, 2021.

17. Fairclough N. Critical Discourse Analysis and Critical Policy Studies // Critical Policy Studies. 2013. Vol. 7.

18. Langacker R. Foundations of Cognitive Grammar: in 2 vols. Stanford: Stanford University Press, 1987. Vol. 1.

\section{Информация об авторах | Author information}

RU Орсоева Аюна Александровна ${ }^{1}$

Серебренникова Евгения Федоровна ${ }^{2}$, д. филол. н., проф.

${ }_{1,2}$ Иркутский государственный университет

EN Orsoeva Aiuna Alexandrovna ${ }^{1}$

Serebrennikova Evgeniia Fyodorovna², Dr

${ }^{1,2}$ Irkutsk State University

${ }^{1}$ orsoeva@inbox.ru, ${ }^{2}$ serebr_ef_76@mail.ru

\section{Информация о статье | About this article}

Дата поступления рукописи (received): 16.10.2021; опубликовано (published): 30.11.2021.

Ключевые слова (keywords): эффективность дискурса; событийность дискурса; аттрактивность; дестинация дискурса; дискурсивный механизм аттрактивизации; discourse effectiveness; discourse eventivity; attractivity; discourse destination; discursive attractivisation mechanism. 